\title{
LA PRIMACÍA DE LA PERSONA: VISIÓN DEL PRINCIPIO CONSTITUCIONAL GUATEMALTECO DESDE EL PERSONALISMO DE JOSEPH RATZINGER
}

The primacy of person: A vision of the Guatemalan constitutional principle from the personalism of Joseph Ratzinger

\section{Juan Pablo Gramajo Castro}

Licenciado en Ciencias Jurídicas y Sociales, Abogado y Notario, Universidad Francisco Marroquín

Maestro en Propiedad Intelectual, Candidato al Doctorado en Derecho, Universidad de San Carlos de Guatemala

jpablogc@ufm.edu https://doi.org/10.37346/opusmagna.v16i01.11

Fecha de recepción: 07/08/2019

Fecha de aceptación: 20/02/2020 


\section{SUMARIO}

\section{Introducción}

1. El iusnaturalismo teológico cristiano

2. Las bases del sistema internacional de derechos humanos

3. El pensamiento de Joseph Ratzinger - Benedicto XVI

4. El personalismo y el constitucionalismo guatemalteco

\section{Conclusiones}

Bibliografía

Resumen
Joseph Ratzinger es un destacado teólogo
que además ejerció la máxima autoridad
eclesiástica. Este ensayo expone cómo
él aborda el derecho en general y,
con ello, los derechos humanos y su
sistema internacional, desde una óptica
iusnaturalista-teológica. Ratzinger
propone una visión del derecho sobre
la base personalista de una antropología
teológico-filosófica en que la persona
humana, libre y racional, es sujeto de
dignidad y derechos por su creación
a imagen de Dios. En consecuencia,
participa tanto de la unidad como de
la diversidad. La unidad fundamenta
la universalidad, indivisibilidad e
interdependencia de sus derechos
fundamentales. La racionalidad hace
posible descubrir normas de justicia, y la
diversidad permite hacerlo en distintos
ámbitos culturales. La condición de
creatura supone límites a la noción
de derechos humanos, la cual debe
complementar junto con la de deberes.
Según Ratzinger -como se expondrá
en el desarrollo del texto- el derecho se
integra en parte por principios y valores
inviolables de la naturaleza humana,
entre los cuales se incluyen los derechos

\begin{tabular}{l} 
Abstract \\
Joseph Ratzinger is a distinguished \\
theologian who also exercised the \\
supreme ecclesiastical authority. This \\
essay presents how he approaches law \\
in general and, with it, human rights \\
and their international system, from \\
a natural law-theological standpoint. \\
Ratzingerproposes a view of the law on \\
the personalist basis of a theological- \\
philosophical anthropology in which \\
the human person, free and rational, \\
is a subject of dignity and rights \\
through creation in the image of God. \\
Consequently, the person participates \\
both in unityand diversity. Unityserves \\
as a foundation for the universality, \\
indivisibility and interdependence \\
of the person's fundamental rights. \\
Rationality enables the discovery of \\
rules of justice, and diversity makes \\
it possible to achieve it in different \\
cultural environments. The condition \\
as a creature implies limits to the \\
notion of human rights, which must be \\
complemented with that of duties. \\
For Ratzinger -as will be shown \\
throughout the text- law consists \\
partly of inviolable principles and \\
values of human nature, among which \\
\hline
\end{tabular}


humanos, y en parte por legítimas determinaciones humanas, cuyo contenido y métodos de formulación pueden variar. Tales métodos deben siempre respetar los derechos humanos y las verdades fundamentales comunes a la humanidad.

Actualmente se favorece como método la deliberación democrática, que no puede reducirse a un consenso de mayorías aritméticas, sino ser sensible a la verdad. En el diálogo democrático, razón y fe están llamadas a purificarse mutuamente. La labor del jurista debe desarrollarse en contacto vital con la realidad. El pensamiento de Ratzinger, al valorar la universalidad humana y la pluralidad de las culturas como bases del orden jurídico y social, ofrece una rica apertura intelectual para comprender los órdenes internacional, nacional y pluralista, así como su interrelación.

Tales nociones pueden ayudar a comprender la primacía de la persona humana y la pluriculturalidad como elemento constitutivo de la sociedad guatemalteca, principios fundamentales del constitucionalismo nacional. Éste propone un Estado con orientación personalista y humanista, al servicio del desarrollo integral de la persona en sus diversos aspectos.

Palabras clave: Derecho Constitucional, Filosofía del Derecho, Derecho Natural, Persona, Personalismo, Diversidad, Derechos Humanos. human rights are included, and partly of legitimate human determinations, whose contents and methods of formulation may vary. Such methods must always respect human rights and fundamental truths common to mankind.

Democratic deliberation is currently favored as a method, which cannot be reduced to a consensus of arithmetical majorities, but be sensible to truth. In democratic dialogue, reason and faith are called to purify each other. The work of a jurist must be carried out in vital contact with reality. Ratzinger's thought, by valuing human universality and cultural plurality as bases of the legal and social order, offers a rich intellectual openness for understanding the international, national and pluralistic orders, as well as their interrelation.

Such notions may aid in understanding the primacy of the human person and the country's multicultural character as a constitutive element of Guatemalan society, fundamental principles of national constitutionalism. This proposes a State with a personalist and humanist orientation, at the service of the integral development of the person in its diverse aspects.

Keywords: Constitutional Law, Philosophy of Law, Natural Law, Person, Personalism, Diversity, Human Rights. 


\section{INTRODUCCIÓN}

El iusnaturalismo es uno de los paradigmas tradicionales del Derecho, acaso el más antiguo y que más ha pervivido a través de la historia. Dicha pervivencia ha adoptado diferentes formas y manifestaciones, que los estudiosos del pensamiento jurídico agrupan bajo diversas corrientes. Entre ellas, la que algunos autores denominan derecho natural teológico, en referencia básicamente a comprender el derecho natural como proveniente de o ligado a una divinidad. Una de las expresiones más difundidas de esta concepción es la que tuvo como base la teología y doctrina de la Iglesia Católica, principalmente en la edad media.

Por las características culturales, sociales y políticas de su época, esta noción influyó profundamente en la configuración de la sociedad europea y, por extensión, de las sociedades coloniales de América y otros continentes. Desarrollos posteriores del pensamiento religioso, político, social y jurídico como la reforma protestante, la ilustración, el positivismo filosófico y jurídico, entre otros- condujeron eventualmente al reemplazo de las bases religiosas de la sociedad por nuevas bases secularizadas.

Todas las bases de la sociedad -incluyendo las filosóficas y jurídicasfueron nuevamente conmovidas en el siglo XX -con una violencia y extensión sin precedentes- por sucesos como las guerras mundiales, los totalitarismos, la Guerra Fría, transformaciones intelectuales y culturales, los movimientos descolonizadores y conflictos armados, etc. En este contexto surge una renovada pugna por la dignidad humana que desemboca en la construcción de un sistema internacional de derechos humanos. Esta perspectiva influye de modo fundamental sobre la Constitución Política de la República de Guatemala promulgada en 1985, que enfatiza los derechos humanos y su consagración internacional, fundándose sobre "la primacía de la persona humana como sujeto y fin del orden social" (Preámbulo y art. $1^{\circ}$ ). 
También en estos nuevos contextos, algunos pensadores católicos ${ }^{1}$ se han sumado a la reflexión sobre la dignidad y derechos de la persona, sobre cómo entenderlos, defenderlos y promoverlos en una época globalizada, secularizada, escéptica de la religión, con protagonismo de diversas culturas y concepciones del mundo. Uno de ellos es Joseph Ratzinger, quien además ejerció el papado con el nombre Benedicto XVI. Su abordaje del derecho, los derechos humanos y el sistema internacional, desde una óptica iusnaturalista-teológica, ofrece algunos aportes al ámbito más amplio del entendimiento y vivencia del Derecho en el mundo contemporáneo y en la realidad nacional. Específicamente, arribando al carácter personalista de su pensamiento como lugar de encuentro con el principio fundamental del constitucionalismo guatemalteco.

1 Como John Finnis y Robert PÁG. George, entre otros, a quienes se agrupa en una nueva corriente del pensamiento iusnaturalista contemporáneo. 


\section{El iusnaturalismo teológico cristiano}

Conviene primero exponer qué se entiende por iusnaturalismo teológico. En su disertación doctoral, el jurista nacional Alejandro Gutiérrez lo aborda entre los paradigmas tradicionales del derecho (2017, Capítulo II), indicando que, en su sentido más general o amplio, el iusnaturalismo

...consiste en sostener conjuntamente estas dos posiciones: a) (...) que hay principios morales y de justicia universalmente válidos y accesibles a la razón humana; b) (...) un sistema normativo o una norma no logran ser calificados de 'jurídicos' si contradicen aquellos principios morales o de justicia. (...) Si bien todos los iusnaturalistas coinciden sustancialmente en defender estas dos teorías, disienten acerca del origen o fundamento de los principios (...) y acerca de cuáles son tales principios. (2017, pág. 39).

Las ideas iusnaturalistas acompañan a la civilización occidental desde sus inicios. En la antigüedad, halla su máximo desarrollo con Aristóteles. En Roma, los juristas desarrollan su noción y aplicación práctica, de la mano del estoicismo. En la edad media, se perfecciona en lo esencial con el pensamiento de Tomás de Aquino. La tradición iusnaturalista cristiana asume los aportes de la antigüedad grecolatina, entendiendo el derecho natural como participación de la criatura racional en la ley eterna de Dios (Gutiérrez, 2017, págs. 39-43; Hervada, 1996, Capítulos I y III).

Después surge lo que Gutiérrez llama iusracionalismo o iusnaturalismo ilustrado (2017, pág. 43). Hervada lo denomina escuela moderna del derecho natural o iusnaturalismo moderno, distinto de la escuela clásica o iusnaturalismo clásico, que a veces se usa para designar sólo el iusnaturalismo escolástico (Tomás de Aquino y continuadores, con algunas variaciones importantes), y otras designa en modo general la "orientación aristotélico-tomista" (Hervada, 1996, pág. 250), que comprende principalmente las enseñanzas de Aristóteles y Tomás de Aquino, junto a las posturas influidas por ellos. El iusnaturalismo ilustrado o moderno surge, entre otros factores, por las guerras religiosas al romperse la unidad religiosa y cultural regida por la Iglesia Católica, el surgimiento y auge del laicismo y del racionalismo (Hervada, 1996, págs. 
253-254), el nacimiento del estado moderno y la centralidad del individuo manifestada como derecho subjetivo (Gutiérrez, 2017, pág. 43). Actualmente hay un iusnaturalismo contemporáneo con diversas corrientes, como la nueva escuela anglosajona del derecho natural (Massini, 2006, Capítulo IV; Gutiérrez, 2017, págs. 45-48).

Específicamente en cuanto al iusnaturalismo teológico, el doctor Gutiérrez afirma que para esta vertiente

... el Derecho natural es aquella parte del orden interno del universo originado en Dios que es asequible a la razón humana. Ningún orden positivo tiene fuerza obligatoria si no concuerda con los principios de derecho natural. (...) no sólo es un derecho que debe ser, sino un derecho verdadero, válido, existente. (...) es universal, aplicable a todos los seres humanos y en todos los tiempos, y necesario, puesto que es inmutable... (2017, pág. 49).

Los resaltados en la cita marcan las características fundamentales del iusnaturalismo teológico. Su máximo exponente es Tomás de Aquino (12241274), fuertemente influido por Aristóteles (384 a.C.-322 a.C.). Otros pensadores importantes son: Agustín de Hipona (354-430), Isidoro de Sevilla (556-636), Pedro Abelardo (1079-1142), Alejandro de Hales (1185-1245), Alberto Magno (1193-1280), Juan Duns Escoto (1266-1308), Buenaventura de Bagnoregio (1217-1274), Guillermo de Ockham (1280-1349), entre otros. (Hervada, 1996, págs. 102-105, 114-116, 139-150, 183-185, 189-191). La influencia de la teología sobre el pensamiento iusnaturalista medieval se debe al carácter cristiano de la cultura de su época. No se trata de una confesionalidad del Estado, de una imposición, ni se reduce a las formas sociales históricas y contingentes en que se produjo (Hervada, 1996, págs. 250-253). Para una sociedad creyente, era natural ver la teología como

... la regina scientarum, en la que toda ciencia -también la ciencia del derecho- encontraba su más radical e íntima explicación. Esto no quiere decir que la ciencia del derecho estuviese absorbida por la teología; [...] una cosa es la autonomía científica y otra cosa es la explicación última de la realidad (Hervada, 1996, pág. 252). 
Una objeción hoy frecuente ante el derecho natural teológico es que, por su vinculación religiosa, sería inaceptable invocarlo en la esfera pública de un estado laico, pues sus formulaciones son creencias particulares que, al usarse como base de una norma jurídica, se impondrían al conglomerado social violando la laicidad estatal y la libertad de conciencia. Por ello es importante recordar que la tradición iusnaturalista cristiana y teológica se desarrolla en un ámbito más amplio enraizado en la antigüedad precristiana, y que uno de sus postulados fundamentales es que el orden natural es accesible a la razón, no exclusivo de la revelación divina. Como lo expone Hervada:

El derecho natural (...) en cuanto idea captada por el pensamiento humano es anterior al cristianismo (...). Ni Aristóteles, ni Cicerón, ni Ulpiano fueron cristianos; el estoico Marco Aurelio les persiguió; Averroes fue musulmán, Maimónides judío, Ahrens, laicista, etc. Es más, (...) se ha utilizado como el lenguaje común a (...) creyentes y no creyentes. (1996, págs. 320-321; ver también: Gutiérrez, 2017, pág. 42).

Quizá sirva considerar el tema desde la teoría propuesta por Wilhelm Dilthey, quien desarrolla tres principales cosmovisiones en su obra Teoría de las concepciones del mundo (1994): (1) La religiosa, en que predomina la voluntad y la relación con lo visible que manifiesta la eficacia de lo invisible; (2) La artística o poética, en que predomina el sentimiento y la relación con el símbolo; (3) La filosófica o metafísica, en que predomina el pensamiento y la relación con el concepto. La concepción filosófica se subdivide en tres corrientes principales: (3.a) Naturalismo, de carácter sensualista, positivista y materialista, que ve al ser humano como determinado por la naturaleza; (3.b) Idealismo objetivo, de carácter inmanente y panteísta, que ve al ser humano como en armonía con la naturaleza; (3.c) Idealismo de la libertad, de carácter trascendente y teísta, que ve al ser humano como consciente de su distinción frente a la naturaleza en virtud de su libre albedrío. Esta, a su vez, tiene dos principales vertientes: (3.c.i) Grecolatina-cristiana; (3.c.ii) Kantiana. (Romero, 2018, pág. 42).

Para Dilthey, la teología puede aproximar la cosmovisión religiosa a la concepción metafísica, pero aquélla tendrá siempre un núcleo que esta labor conceptual nunca podrá explicar ni fundamentar. Aun así, clasifica a algunos pensadores cristianos, especialmente primitivos, dentro del idealismo de la 
libertad, una cosmovisión no religiosa sino filosófica, nacida con Anaxágoras, Sócrates, Platón y Aristóteles, que incluye además a Cicerón, el estoicismo, Kant, Bergson, entre otros. Aunque muy diversos entre sí, los representantes de esta corriente tienen en común su concepción del espíritu como libre: independiente de causalidad física, pero ligado por normas que lo obligan íntimamente como ley y, por ende, lo hacen sujeto de responsabilidad. Un aporte específico del pensamiento cristiano a esta concepción es la idea de la creación, que concibe a la divinidad como personal y trascendente frente a la causalidad (Dilthey, 1994, págs. 53, 72-76). En lo jurídico, esto se traduce en dos ideas -procedentes ya del Antiguo Testamento- básicas para la teoría del derecho natural: la "existencia de Dios como ser personal y, por tanto, distinto del mundo" (Hervada, 1996, pág. 84) y la consiguiente naturaleza personal del hombre, dotado por tanto de libertad, discernimiento y responsabilidad (1996, págs. 85-86).

Bajo esta luz, el iusnaturalismo teológico cristiano podría verse desde sus inicios- como parte de una tradición filosófica que no se reduce a una cosmovisión exclusivamente religiosa, sino partícipe de las fuentes más preclaras del pensamiento occidental, a cuyo desarrollo también ha realizado aportes relevantes. Sería una corriente que, si bien busca la luz de la teología como explicación última, lo hace convencida de que la razón humana es capaz por sí sola de descubrir un orden natural al que debe ceñirse. Por tanto, busca hablar el lenguaje de la razón como medio para entrar en diálogo más allá de la fe. Es ese diálogo racional el que Ratzinger buscará entablar con el hombre y el mundo contemporáneos.

\section{Las bases del sistema internacional de derechos humanos}

La experiencia de las guerras mundiales motivó la creación de la Organización de las Naciones Unidas en 1945, con la intención de evitar futuras guerras, "reafirmar la fe en los derechos fundamentales del hombre, en la dignidad y el valor de la persona humana" (Carta de las Naciones Unidas, Preámbulo), y fomentar la cooperación internacional para el respeto de los derechos humanos y las libertades fundamentales, sin excepciones (Artículos 1.3, 13.1.b, 55.c, 62.2, entre otros). En 1948, la Asamblea General adoptó la Declaración Universal de Derechos Humanos, hecho que "colocando a los derechos humanos al 
lado del principio de soberanía (...) significó la transformación del Derecho internacional clásico, concebido por y para Estados, produciéndose una erosión y relativización del principio de soberanía" (Red de Derechos Humanos y Educación Superior, 2013, pág. 91). Para Pedro Nikken, ex presidente de la Corte Interamericana de Derechos Humanos,

El derecho internacional de los derechos humanos es un derecho ideológico, en el sentido de que parte de la noción de la superioridad de los atributos inherentes a la dignidad humana, cuya inviolabilidad debe ser respetada en todo momento por el Estado. Las bases filosóficas de esa idea pueden ser de la más diversa índole y hasta contradictorias, pero el concepto de la preeminencia de la dignidad inherente a la persona se nos presenta como un acervo de la civilización, como un todo que aspira expresar una ideología común de la humanidad (2010, pág. 83).

Esto es importante para el tema examinado, pues apunta a debates en torno a los derechos humanos, que pueden ser no sólo vistos y justificados sino también -más relevante- cuestionados desde distintas perspectivas filosóficas, permitiendo arribar a soluciones distintas para cuestiones de gran trascendencia jurídica y social. Es frecuente, por ejemplo, citar las concepciones iusnaturalistas como precedentes históricos o incluso como fundamentos inmediatos de los derechos humanos, con expresiones que pueden remontarse hasta la antigua democracia ateniense y el iusnaturalismo aristotélico, la república romana y la filosofía estoica, la cristiandad medieval y el pensamiento escolástico, o las revoluciones que inauguraron el constitucionalismo moderno en Estados Unidos y Francia, inspiradas por las vertientes insulares y continentales del iluminismo con figuras como John Locke, Jean Jacques Rousseau o Immanuel Kant. Sin embargo, aunque 'internamente' se distinga entre corrientes iusnaturalistas racionalistas y teológicas, clásicas y modernas, etc., éstas pueden en conjunto ser objeto de crítica 'externa' en tanto consideradas específicamente occidentales, haciéndose sospechosas de 'colonialismo intelectual' frente a tradiciones orientales, americanas prehispánicas, etc. Además, el laicismo de algunas manifestaciones del iusnaturalismo racionalista las puede hacer difíciles de conciliar, no sólo con el iusnaturalismo teológico cristiano u occidental, sino con concepciones como el islam, el hinduismo, o las religiones tradicionales de pueblos indígenas y tribales en distintas partes del mundo. 
Samuel Moyn (2010) considera los derechos humanos en la actualidad como un 'universalismo' nuevo, distinto de los anteriores (estoicismo, cristianismo, iusnaturalismo, liberalismo revolucionario), criticando la narrativa tradicional que ve éstos como antecedentes de los cuales aquéllos serían culminación. También cuestiona la narrativa según la cual el sistema nace en la década de los cuarenta con la Organización de las Naciones Unidas y la Declaración Universal, como momento de acuerdo global luego de los horrores de las guerras mundiales: si bien históricamente existió esa aspiración, no fue fácil alcanzar consensos, y no se hicieron efectivos debido -entre otros factores- a la preponderancia del enfrentamiento entre las superpotencias de la Guerra Fría. Para él, en cambio, el verdadero nacimiento de la actual ideología de derechos humanos habría ocurrido en la década de los setenta, lo cual Bass (2010) identifica con la llamada 'tercera ola de democratización' propuesta por el célebre politólogo Samuel Huntington. Otros autores, como Jensen (2016), han argumentado que el impulso contemporáneo de los derechos humanos ocurrió con los movimientos descolonizadores de la década de los sesenta. Quizá ni las historias 'alternativas' ni la 'tradicional' de los derechos humanos sean definitivas o perfectamente acertadas (Bass, 2010), pero son puntos de vista interesantes que hacen tomar conciencia de la complejidad del tema y los matices que su estudio requiere. En cualquier caso, la diferencia radical de los derechos humanos sería que se caracterizan esencialmente por ser oponibles contra los Estados desde fuera, más allá de su soberanía, mientras que universalismos anteriores (concretamente la tradición revolucionaria de los 'derechos del hombre') los concebían como base para la legitimación del Estado hacia adentro, garantizados por el Estado y la soberanía (Moyn, 2010, pág. 23-26).

El debate sobre los fundamentos e historia de los derechos humanos que es filosófico pero también político- se produjo ya cuando nacía el sistema internacional, como han evidenciado estudios sobre el proceso de elaboración de la Declaración Universal (Glendon, 2002) y de la encuesta de la Organización de las Naciones Unidas para la Educación, la Ciencia y la Cultura² sobre derechos humanos (Goodale, 2018). El hecho mismo de haberse consagrado en dos

2 UNESCO. 
pactos distintos obedece a un momento histórico de polarización ideológica global:

Para el bloque liderado por los Estados Unidos, el ejercicio de las libertades individuales (...) dentro de una economía de mercados, cimentaría la prosperidad dentro de la cual las necesidades humanas de naturaleza económica, social y cultural podrían quedar satisfechas. Los [derechos económicos, sociales y culturales] no resultaban (...) equiparables a los derechos civiles y políticos, pues estos eran verdaderos derechos subjetivos (...), mientras que los primeros sólo reflejarían aspiraciones (...) logrables, no a través del sistema legal sino de los mecanismos propios de la economía y de las políticas públicas (...). Para el bloque liderado por la Unión Soviética, en cambio, dominado por la economía estrictamente planificada y centralizada, (...) si las necesidades socioeconómicas básicas no estaban resueltas, los derechos civiles y políticos se concretarían en un privilegio para la burguesía (...), de modo que los derechos económicos, sociales y culturales no sólo eran derechos subjetivos exigibles, sino aquellos a cuya satisfacción el Estado debía atender (...) incluso al precio de restricciones de envergadura a los derechos individuales y las libertades fundamentales. (Nikken, 2010, pág. 65).

En este contexto, Karel Vasak propuso en 1977 la teoría de las tres generaciones de derechos humanos: ( $\left.1^{\mathrm{a}}\right)$ civiles y políticos; $\left(2^{\mathrm{a}}\right)$ económicos, sociales y culturales; $\left(3^{a}\right)$ colectivos o de solidaridad. Ahora se enfatiza que todos los derechos humanos son indivisibles e interdependientes, abandonándose la idea de 'generaciones' por no reflejar tales caracteres. No obstante, por la amplia difusión que alcanzó aquella teoría, nuestra Corte de Constitucionalidad la ha invocado tan recientemente como 2017 (Expediente 5956-2016, por ejemplo), o la Procuraduría de los Derechos Humanos sigue acudiendo a ella para catalogarlos (en sitio de red oficial de la institución) a pesar de que autores la consideran superada. Para algunos, puede conservar cierta utilidad didáctica como aproximación a su desarrollo histórico; para otros, es una tergiversación de su historia. En cualquier caso, se tiende hoy a estimarla abandonada, cuando no inútil y obsoleta (Nikken, 2010, pág. 66; Red de Derechos Humanos y Educación Superior, 2013, pág.104; Jensen, 2017). 


\section{El pensamiento de Joseph Ratzinger-Benedicto XVI}

Un punto de partida imprescindible para comprender el pensamiento de Ratzinger es su convencimiento de que "La fe católica es (...) razonable y nutre confianza también en la razón humana" (Ratzinger, 2012a). Sobre esa línea, expone que el pensamiento griego entró en contacto con la fe bíblica incluso antes del cristianismo, durante el Antiguo Testamento. En Grecia existían tres clases de teología: mítica (poética), civil (política) y natural (filosófica). Las primeras dos corresponden al ámbito que hoy llamaríamos religioso o del culto; la tercera es indagación racional que desemboca en el llamado 'dios de los filósofos', como la idea aristotélica del 'primer motor'. Para Ratzinger, la particularidad de la fe bíblica -y del cristianismo- radica en que apela al Dios racional, metafísico, absoluto, de la teología natural filosófica, pero haciéndolo accesible, 'apelable', revelado en la persona de Jesucristo (2006a, pág. 20-32). A su criterio, los credos formulados por los antiguos concilios usaron terminología filosófica griega, no por convertir la fe en una teoría filosófica, sino para dar forma verbal a dos aspectos esenciales de la fe: (i) su realismo, rechazando una interpretación simbólica o mitológica; (ii) su racionalidad, pues, aunque sobrepase la razón, apela a ella y se presenta con la exigencia de enunciar la verdad. La filosofía griega se caracterizaba por no contentarse con las religiones tradicionales ni los mitos, sino buscar la verdad sobre el ser y el universo: así, al expresarse mediante un lenguaje filosófico, el cristianismo primitivo se presentaba como distinto de las cosmovisiones religiosas tradicionales y como mensaje de verdad sobre el hombre y el mundo (2005a, págs. 83-85). Aquella 'Ilustración' griega también condujo a indagar las razones más profundas del derecho, abandonando el fundado sobre las religiones tradicionales (2008f, págs. 44-45). Desde esta óptica, el iusnaturalismo teológico cristiano aparece, en cierto sentido, también como una forma de iusnaturalismo racionalista: "La elaboración y la estructuración del derecho no es inmediatamente un problema teológico, sino un problema de la recta ratio, de la recta razón" (Ratzinger, 1999). Considera "un problema secundario" si al "derecho en si" -lo justo discernido por la razón- se le ha de llamar derecho natural o de otra forma (1999), pues la idea de derecho natural "ha dejado de ser fiable" ya que "presuponía un concepto de naturaleza en el que la naturaleza y la razón se entrelazaban y en el que la naturaleza misma era racional" (2008f, págs. 46-47), noción que se ha abandonado con la teoría de la evolución. 
Es necesario examinar también cómo Ratzinger concibe la razón humana. Hace una crítica de las filosofías positivistas inspiradas en la Ilustración, específicamente por su carácter anti-metafísico, considerando que expresan sólo parcialmente la razón humana y, por tanto, no son 'plenamente' racionales sino incompletas (2005b). Al excluir del ámbito estricto de la razón todo lo no verificable, las visiones positivistas excluyen "las fuentes clásicas de conocimiento del ethos y del derecho" (2011), las realidades humanas se vuelven extrínsecas a las instituciones jurídicas entendidas como limitadas a su validez formal, creándose "una ruptura entre derecho y existencia humana que niega radicalmente la posibilidad de una fundación antropológica del derecho" (2007a). Sin embargo, también reconoce aportes valiosos de la cosmovisión positivista como "una parte grandiosa del conocimiento humano y de la capacidad humana" (2011), afirmando que no se debe retroceder ni renunciar a los triunfos de la época moderna y de la Ilustración, mediante una crítica negativa, sino ampliar el concepto de razón (2006b). Su convicción sobre la razonabilidad de la fe y la amplitud de la razón origina una actitud de apertura al diálogo como "el medio a través del cual los diversos sectores de la sociedad pueden articular su propio punto de vista y construir el consenso" (Ratzinger, 2008a), diálogo amplio entre las ciencias, culturas y religiones, del que la teología también debe tomar parte (2006b).

Sus reflexiones sobre la razón humana en general tienen relevancia específica para lo jurídico, ámbito que, según él, atraviesa dos principales riesgos en la época actual: (i) El abandono de la metafísica, que conduce al positivismo jurídico, a pensar que "No es la verdad la que crea el consenso, sino que es el consenso el que crea tanto la verdad cuanto los ordenamientos" (1999), reduciendo la determinación de lo justo a simples mayorías; (ii) La disolución del derecho por el influjo de pensamientos utópicos, en que la imagen de una supuesta sociedad perfecta se convierte en la única fuente admisible del derecho (1999). Parte importante de su visión jurídica se basa en distinguir entre materias según comprometan o no la dignidad humana. Para aquellas que no la ponen en juego -que son, según él, gran parte de lo que el derecho debe regular-, el criterio de la mayoría puede ser suficiente (2011). Sin embargo, también afirmó -citando a Jürgen Habermas y reiterando ideas que expuso en el coloquio que con él sostuvo- que la forma razonable de resolver divergencias políticas, como 
fuente de legitimidad y legalidad, no puede limitarse a una lucha por mayorías numéricas, pues "también las mayorías pueden ser ciegas o injustas" (2008f, pág. 39), sino que ha de ser un proceso argumentativo "sensible a la verdad" (2008b), por encima de la sensibilidad por los intereses. Los compromisos políticos no pueden ser meramente aritméticos o de interés, sino basarse "en el reconocimiento de verdades universales, arraigadas en una reflexión razonada sobre los postulados de nuestra humanidad común" (2008c).

Ahora bien, para aquellas "cuestiones fundamentales del derecho" (2011) en que sí entra en juego la dignidad humana, no basta el principio de la mayoría. Menciona el derecho natural, aunque reconoce que la idea es vista hoy como una doctrina específicamente católica, que no tendría lugar fuera del ámbito religioso. Aunque no desarrolla una teoría sobre el contenido del derecho natural, sí destacó algunos aspectos como principios y valores no negociables, inscritos en la naturaleza humana $y$, por tanto, comunes a la humanidad independientemente de la afiliación religiosa:(i) protección, respeto y defensa de la vida humana desde la concepción hasta la muerte natural; (ii) reconocimiento y promoción de la familia natural, fundada en el matrimonio entre un hombre y una mujer; (iii) protección del derecho de los padres a educar libremente a sus hijos; (iv) promoción del bien común en todas sus formas (Ratzinger, 2006c, 2007b). También los derechos humanos, rectamente entendidos, constituyen límites al criterio de las mayorías (2008f, págs. 39-40). Su visión de este tema entronca con la antes expuesta sobre realismo y racionalidad de la fe, afirmando que:

...el cristianismo nunca ha impuesto al Estado y a la sociedad un derecho revelado, un ordenamiento jurídico derivado de una revelación. En cambio, se ha remitido a la naturaleza y a la razón como verdaderas fuentes del derecho, se ha referido a la armonía entre razón objetiva y subjetiva, una armonía que, sin embargo, presupone que ambas esferas estén fundadas en la Razón creadora de Dios (2011).

Expresa este carácter del derecho natural -en términos quizá más comprensibles para nuestra época- como análogo a las cuestiones ecológicas que hoy ocupan tanta atención: 
...hay también una ecología del hombre. También el hombre posee una naturaleza que él debe respetar y que no puede manipular a su antojo. (...) no es solamente una libertad que él se crea por sí solo. (...) no se crea a sí mismo. Es espíritu y voluntad, pero también naturaleza, y su voluntad es justa cuando él respeta la naturaleza, la escucha, y cuando se acepta como lo que es (...). (...) sólo de esta manera, se realiza la verdadera libertad humana. (2011)

Estima que -así como el cristianismo primitivo adoptó el lenguaje filosófico para expresar su realismo y su racionalidad- los teólogos cristianos de los primeros siglos no elaboraron una doctrina iusnaturalista nacida de la revelación, sino que se sumaron al movimiento filosófico y jurídico que venía ya del siglo II a.C. y se había desarrollado con el pensamiento estoico y el derecho romano. El planteamiento iusnaturalista cristiano no nace directamente de la teología o de la revelación; por el contrario, los teólogos cristianos tomaron "posición contra el derecho religioso, requerido por la fe en la divinidad, y se hayan puesto de parte de la filosofía, reconociendo a la razón y la naturaleza, en su mutua relación, como fuente jurídica válida para todos" (2011), como ya lo había hecho san Pablo en la Carta a los Romanos. En consecuencia, sostiene que "La tradición católica mantiene que las normas objetivas para una acción justa de gobierno son accesibles a la razón, prescindiendo del contenido de la revelación" (2010). Especialmente desde el siglo XIX se fue retomando una visión aristotélica -que, indica Ratzinger, tuvo poca importancia en la Iglesia medieval- basada en un doble orden (natural y sobrenatural), en que el ordo naturalis se considera completo en sí mismo, aprehensible de modo puramente racional, que no ha sido destruido completamente por la herida del pecado. Sobre esta visión sería posible "Hacer valer lo verdaderamente humano allí donde la pretensión de la fe no puede ni debe elevarse" (2018, pág. 7). Sin embargo, advierte que la autonomía del ordo naturalis no puede llevar a considerarlo cerrado en sí mismo y autosuficiente, pues se corre el riesgo de "reducir lo propiamente cristiano a lo puramente sentimental" (2018, pág. 8), olvidando la realidad del pecado original, lo cual conduce a formas de optimismo ingenuas e irrealistas, incluyendo una ingenua confianza en la razón que no percibe la complejidad de la conciencia en el ámbito ético (2018, págs. 8-9). 
Es por eso que ver el derecho natural, 'derecho en si' o el 'ordo naturalis', como accesibles a la razón prescindiendo de la revelación no implica, para Ratzinger, que el cristianismo o la religión en general dejen de tener un papel en estas cuestiones. Consciente de las dificultades que ello conlleva en la actualidad, indica que su papel no consiste ni en proporcionar las normas (precisamente porque, al ser accesibles a la razón, pueden conocerlas los no creyentes), ni mucho menos en proponer soluciones políticas concretas (cosa que estima "totalmente fuera de la competencia de la religión") (2010). En cambio, consiste en "ayudar a purificar e iluminar la aplicación de la razón al descubrimiento de principios morales objetivos" (2010), forjar el debate público e iluminar la dimensión moral intrínseca en las cuestiones sociales (2008c), conservando la capacidad de la razón para ver y percibir (1999). Pero, a la vez, propone un intercambio en doble sentido por el cual la razón también ayude a la religión a purificarse, para evitar el sectarismo y el fundamentalismo (2010; 2008f, págs. 52-53). Sobre esa línea, afirma que la fe no puede ser fundamento de un derecho estatutario, y que aquella respeta la naturaleza propia del Estado y de una sociedad pluralista, pero sin renunciar a su responsabilidad a efecto de que los fundamentos del derecho sigan siendo visibles (1999). En definitiva, la pregunta por las cuestiones más trascendentales de la existencia seguirá siendo ineludible, como expresa Ratzinger al afirmar:

...el Kelsen de la última etapa tenía razón cuando decía que derivar un deber del ser solo es razonable si Alguien ha puesto un deber en el ser. Para él, sin embargo, esta tesis ni siquiera merece ser discutida. A fin de cuentas, me parece que todo consiste a la postre en el concepto de Dios. Si Dios existe, si hay un creador, entonces el ser puede también hablar de él y manifestar al hombre un deber. Si no existe, entonces el ethos se reduce finalmente a pragmatismo. (...) La idea de los derechos humanos conserva, a fin de cuentas, su solidez solamente si está arraigada en la fe en el Dios creador. Desde allí recibe ella su limitación y, a la vez, su fundamento. (2018, págs. 8-9)

Con esto, su pensamiento se dirige también hacia los derechos humanos y el sistema internacional construido para su salvaguarda. Ratzinger se refiere a Kant al hablar de los elementos constitutivos de la idea de los derechos humanos, brindándoles una interpretación cristiana y una fundamentación bíblica: 
...en la doctrina de la imagen de Dios en el hombre está contenido sustancialmente lo que Kant expresaba cuando definía al hombre como fin y no como medio. Se podría decir también que estaba contenido que el hombre es sujeto de derecho y no solamente objeto de derecho. Me parece que en Gén 9,5ss se expresa claramente este elemento constitutivo de la idea de los derechos humanos: «Y al hombre le pediré cuentas de la vida de su hermano. Quien derrame la sangre de un hombre, por otro hombre su sangre será derramada; porque a imagen de Dios hizo él al hombre». La imagen de Dios en el hombre implica (...) que él es, frente a las leyes humanas, portador de un derecho fijado por Dios mismo (2018, pág. 5)

Se refiere a la idea de los derechos humanos como anteriores al Estado y oponibles ante él, al reseñar la importancia que el tema adquirió en el magisterio eclesiástico a partir de Juan Pablo II, quien -a juicio de Ratzinger- "ha afirmado la consecución de los derechos humanos como una fuerza reconocida por la razón universal contra las dictaduras de cualquier tipo" (2018, pág. 4), no sólo en continuidad con la experiencia de la iglesia primitiva ante el Estado romano (que exigió la libertad de la conciencia individual como límite a la autoridad estatal), sino movido además por su experiencia personal ante el marxismo del siglo XX. El desarrollo del concepto de derechos humanos, para Ratzinger, tiene como base la convicción de la existencia de un Dios creador $(2011,2018)$, y son el último elemento que queda de la noción tradicional de derecho natural (2008f, pág. 48).

Ve los derechos humanos como formulaciones estables de elementos normativos que deben ser respetados incluso por las mayorías, aunque reconoce los cuestionamientos que se les hacen desde algunas tradiciones religiosas o culturales (2008f, págs. 39-40). Desarrolló su visión sobre el sistema internacional de los derechos humanos en alocución ante la Asamblea General de las Naciones Unidas con ocasión del $60^{\circ}$ aniversario de la DUDH (2008a). En ella, expuso que la DUDH resultó de "una convergencia de tradiciones religiosas y culturales (...) motivadas por el deseo común de poner a la persona humana en el corazón de las instituciones, leyes y actuaciones de la sociedad" (2008a), afirmando expresamente que los derechos humanos "se basan en la ley natural inscrita en el corazón del hombre y presente en las diferentes culturas y 
civilizaciones" (2008a). Para él, los caracteres de universalidad, indivisibilidad e interdependencia garantizan la salvaguardia de la dignidad humana, enfatizando que no sólo los derechos humanos son universales sino también lo es -y con más importancia-la persona humana, su sujeto. Este énfasis busca guardar contra una relativización de los derechos humanos, al arrancarse del contexto de sus fundamentos éticos y racionales, de la ley natural y la dignidad de la persona: los derechos humanos, dice, tienen indivisibilidad, porque su sujeto, la persona humana, tiene unidad. Así, reafirma la validez para todos los tiempos y todos los pueblos de la máxima no hagas a otros lo que no quieres que te hagan a ti (2008a). Sobre este tema ha vuelto más recientemente:

El concepto de Dios implica un concepto fundamental del hombre como sujeto de derecho; funda y limita, con ello, a la vez la idea de los derechos humanos. (...) La multiplicación de derechos conduce finalmente a la destrucción del concepto de derecho y acaba en un «derecho» nihilista del hombre de negarse a sí mismo -aborto, suicidio, producción del hombre como una cosa se convierten en derechos del hombre, que a la vez lo niegan-. (2018, págs. 9-10).

En otra oportunidad, propuso la necesidad de reformar la ONU para dar "concreción real al concepto de familia de naciones (...), encontrar formas innovadoras para poner en práctica el principio de la responsabilidad de proteger y dar (...) voz eficaz en las decisiones comunes a las naciones más pobres" (2009). Abogó entonces por una autoridad política mundial con miras a la economía global, el desarme integral, la seguridad alimenticia y la paz, la salvaguardia del medio ambiente y la regulación migratoria. Tal autoridad debería ser gobernada por el derecho, ordenada al bien común y basada en los principios de subsidiaridad y solidaridad, con poder efectivo para garantizar la seguridad, la justicia y el respeto de los derechos, a fin de que el derecho internacional no quede condicionado a los equilibrios de poder entre los más fuertes (2009).

Reflexionando desde el ámbito particular del derecho canónico, Ratzinger ha valorado la actividad judicial como generadora de predictibilidad y confianza, que favorezcan el desarrollo de la vida social mediante la unificación de la jurisprudencia (2008d). Para ello, estima que el jurista no puede olvidar 
que "la hermenéutica del derecho (...) está estrechamente vinculada a la concepción misma de la ley" (2012b). Por eso invita a ver el derecho como más que un conjunto de reglas positivas a aplicar, concibiendo la labor judicial como ejercicio de la prudentia iuris que lea relaciones específicas de justicia en los acontecimientos, sin convertirlo en "reglas abstractas y repetitivas, expuestas al peligro de interpretaciones subjetivas y arbitrarias" (2008d). Si el derecho se agotara en el sistema de leyes, el intérprete quedaría privado del contacto vital con la realidad.

Sin embargo, rechaza también las corrientes hermenéuticas que, a su criterio, superan el legalismo pero no el positivismo, por cuanto proponen una labor interpretativa que puede tornarse arbitraria en un afán por adaptarse a cualquier solución, por encima de la búsqueda de un derecho objetivo. Aboga, en cambio, por entender la ley humana como expresión de justicia, en lo que manifiesta tanto de derecho natural como de legítima determinación humana. Ratzinger designa esta hermenéutica como 'realista', pues no se reduce a un mero ejercicio lógico, sino busca armonizar el significado propio de la ley (que incluye contemplar la realidad que regula) con la pregunta sobre lo justo en cada caso concreto (que incluye aspectos de derecho tanto natural como humano), admitiendo la posibilidad de que existan circunstancias concretas que exijan soluciones equitativas que la norma general no pudo prever (2012b). Son trazos generales que ofreció como orientación al máximo tribunal en materia canónica, por lo que no los desarrolla de modo técnico-científico. No obstante, como propuesta para materializar su visión sobre el derecho en la práctica jurídica real, son un punto de partida valioso que amerita mayor exploración por el pensamiento jurídico, no sólo canónico sino en general.

Otro aporte significativo es el énfasis que hace sobre la dimensión intercultural, que estima indispensable "para plantear la discusión sobre las cuestiones fundamentales del hombre, que no se puede entablar pura y simplemente entre cristianos ni únicamente dentro de la tradición racionalista occidental" (2008f, pág. 49). Partiendo de reconocer la falta de universalidad de facto de los dos universalismos occidentales (cristianismo, racionalismo laico), insiste en la necesidad de que se abran no sólo el uno al otro (diálogo razón-fe), sino a las demás culturas (diálogo intercultural). Como explica 
Blanco comentando el pensamiento de Ratzinger, también esto se origina en la centralidad de la persona humana como imagen de Dios:

Dios es uno y distinto al mismo tiempo: la pluralidad forma parte de la Trinidad tanto como la unidad. Como consecuencia, también en la persona humana se conjugan ambas instancias: lo uno y lo múltiple, la unidad y la diversidad. El pluralismo y el reconocimiento de la legítima diversidad presentan también un origen teológico. (2012, pág. 25).

\section{EI personalismo y el constitucionalismo guatemalteco}

El personalismo es una corriente del pensamiento cristiano que influyó sobre las primeras conceptualizaciones de los derechos humanos a través de pensadores como Jacques Maritain, quien tuvo un papel importante en el ya mencionado simposio de la Organización de las Naciones Unidas para la Educación, la Ciencia y la Cultura (Moyn, 2010, págs. 64-68, 74-76; Burgos, 2010). Se origina en la Europa de entreguerras, como esfuerzo de pensadores judeo-cristianos para responder a la problemática sociocultural en un contexto dominado por el cientificismo, el positivismo, el liberalismo, los colectivismos, el retroceso de la cultura cristiana y la modernidad filosófica. Decae en la década de los sesenta a raíz de la crisis posterior al Concilio Vaticano II, el marxismo, la revolución intelectual y cultural del '68, la revolución sexual, etc., hasta experimentar un renacimiento a partir de la década de los noventa (Burgos, 2010, págs. 8-18). La antropología teológica y filosófica de Ratzinger tiene presupuestos personalistas (Buriticá, 2014, pág. 486). La persona es un "principio estructurante" de su pensamiento, siendo partidario del personalismo y del existencialismo, con influencias de san Agustín, Karl Jaspers, Martin Heidegger y Martin Buber (Blanco, 2012, págs. 24-25). Para Ratzinger -citando a Antonio Rosmini- "La persona humana es la esencia del derecho" (2008e).

La noción de persona nace en la teología cristiana, sobre bases del pensamiento griego y del derecho romano. La palabra griega $\pi \rho \circ \sigma o \pi o v$ (prósopon) designaba originalmente la máscara usada por los actores teatrales paraidentificar el papel que representaban. Por servir también como instrumento de resonancia para la voz de los actores, en latín se designó como per-sonare. La palabra para designar la máscara se hizo extensiva al papel y al actor, al hombre. 
Otra posible acepción proviene del latín per se sonans: el que habla por sí mismo, con voz propia, que en el derecho romano significaba el varón libre sui iuris. El cristianismo siembra las raíces para ampliar el concepto jurídico de persona, al proclamar la igualdad entre hombre y mujer, libre y esclavo, etc. También elabora el concepto filosófico-teológico de persona para definir los dogmas cristológico y trinitario, concibiéndola como substancia o unidad singular subsistente en sí misma, consciente de su ser sin referencia a otra cosa (es decir, no accidental), que además tiene como propio lo relacional. La naturaleza, en cambio, designa lo común o general. Boecio (480-525) sintetiza estas tradiciones en su conocida definición de persona como substancia individual de naturaleza racional.

La escolástica estudió a la persona enfatizando su carácter sustancial, lo cual le impidió desarrollar otros como su dimensión interior y subjetiva. El renacimiento reivindica al hombre como individuo y sujeto creador, pensado no sólo en su dimensión religiosa sino terrena, caracterizado por su libertad. Con la llegada del racionalismo cartesiano y otras corrientes, el término persona es desplazado por el de sujeto, que reemplaza la noción medieval y renacentista por la del yo, la conciencia -ser interior consciente de sí mismocomo principio determinante del conocimiento y la acción, dando menor relevancia a lo relacional. El sujeto trascendental kantiano llega a entenderse como una entidad abstracta, alejada en cierta forma del hombre concreto. El yo esencial hegeliano se entiende como autoconciencia de un espíritu absoluto y no de un yo específico de cada hombre. Estas aportaciones, aunque importantes, se desarrollan desde una perspectiva idealista, haciéndoles difícil relacionarse con las concepciones realistas de la tradición anterior (Burgos, 2009, págs. 26-34; Buriticá, 2014, págs. 470-477).

La noción moderna de sujeto lo ve como configurador de sus objetos de conocimiento y de voluntad, buscando una ciencia que lo haga dueño y señor de la naturaleza, sobre la cual tendrá una función constructiva y no ya contemplativa, de tal forma que todo adquiere sentido con referencia al sujeto absolutamente autónomo, especialmente la ética personal o social. Es por ello que algunos han criticado la noción de derechos humanos como "prerrogativas inherentes al sujeto, previas a su vida social y sin fundamento trascendente alguno", nacidos de la filosofía de la conciencia y la teoría del sujeto. La posmodernidad, por su 
parte, propone la liberación como sobrepasar el sujeto: éste ya no da sentido a la realidad, sino que ella carece de sentido, con lo cual también desaparece la noción de derechos humanos, disuelta en relaciones fácticas sin sentido deóntico (Massini, 2006, págs. 104-105, 107, 109-110). El personalismo busca rescatar la noción de persona de los extremos colectivistas e individualistas, adoptando los aportes filosóficos de la modernidad (conciencia, sujeto, yo, libertad, etc.), en un marco realista abierto a la trascendencia (Burgos, 2009, págs. 34-38).

El Preámbulo de la Constitución Política de la República de Guatemala -como explica el renombrado constitucionalista patrio García Laguardiacontiene "los principios, la filosofía de la Constitución, la ideología que la inspira. [...] se expresan los valores superiores que informan el ordenamiento jurídicoconstitucional", entre ellos "la dignidad de la persona humana (...)" (2015, pág. 100). Ramiro de León Carpio -quien presidió tanto la llamada Comisión de los Treinta como la Asamblea Nacional Constituyente- coincide en que el Preámbulo sintetiza el espíritu, objetivos y valores constitucionales, y destaca que "La característica fundamental y el espíritu contenido en el preámbulo (...) podemos resumirla así: Es eminentemente personalista y humanista ya que se fundamenta en el principio de protección a la persona humana" (S.F, págs. 17$18)$.

En la misma línea, la Corte de Constitucionalidad ha estimado que el Preámbulo "contiene una declaración de principios por la que se expresan los valores que los constituyentes plasmaron en el texto" (Expediente 12-86, sentencia de 17 de septiembre de 1986) y "constituye el enunciado éticopolítico del sistema" (Expediente 2567-2015, sentencia de 31 de marzo de 2016) (positivado especialmente en los artículos $1^{\circ}$ al $5^{\circ}$ ), de cuyo contenido se deducen "los presupuestos, ideales, principios y valores del Estado constitucional y democrático de Derecho" (Expediente 2953-2009, sentencia de 22 de febrero de 2011). El primer principio que se afirma dentro del Preámbulo es "la primacía de la persona humana como sujeto y fin del orden social”, por lo cual el Estado se organiza para su protección (Artículo $1^{\circ}$ ) y recibe el deber de garantizar su desarrollo integral (Artículo $2^{\circ}$ ). Sobre el artículo $1^{\circ}$ de la Constitución, la Corte ha manifestado expresamente que "es el reflejo del espíritu personalista 
de la Constitución y de los valores sobre los cuales se cimentó el Estado de Guatemala: un Estado humanista cuya organización se dirige hacia la protección de los derechos humanos" (Expediente 5956-2016, sentencia de 5 de octubre de 2017). Además, de manera en principio congruente con la noción general del personalismo, la Corte ha considerado que la primacía de la persona no se limita a un carácter individualista (Expediente 12-86, sentencia de 17 de septiembre de 1986) ${ }^{3}$.

El Preámbulo y los artículos relacionados fueron discutidos especialmente en la llamada Comisión de los Treinta, que debatió el anteproyecto de Constitución, aunque también hubo algunas referencias de interés en las sesiones de la Asamblea Nacional Constituyente. En los Diarios de Sesiones de la Comisión (Tomo I, No. 2) se designa la primacía de la persona como "un principio fundamental (...) de carácter antropológico" (pág. 5, González Quezada), inspirado en un pensamiento o filosofía humanista que pone el Estado al servicio del hombre (pág. 10, Soberanis; pág. 15, de León Vargas), afirmando que la Constitución busca "evitar el abuso de poder del Estado en contra de la persona humana o en contra del individuo" (pág. 14, Molina Mencos). Aunque en este $\mathrm{u}$ otros pasajes parece que 'persona humana' e 'individuo' se emplean como sinónimos, en otros se afirma que no se habla de individuo sino de persona, para expresar tanto su dimensión individual como social (pág. 10, Soberanis).

La Constitución se planteó como antropocéntrica, dando a la persona preeminencia sobre el Estado, entendiendo al hombre no sólo en su dimensión material sino también espiritual, que implica una apertura a la trascendencia (Tomo I, No. 3, pág. 23, Soberanis); como anterior al Estado y a la sociedad, con derechos inalienables (Tomo I, No. 4, pág. 15, López Vidaurre); como ser espiritual y material dotado de existencia, trascendencia, indigencia (necesidades), dignidad esencial y valor intrínseco por su condición humana, sociabilidad, y capacidad de dirigir su vida mediante acción inteligente y libre (págs. 12-13, Alonzo Barillas). Tal Constitución antropocéntrica tendría

3 Sin embargo, nos parece que en dicha sentencia puede haber deficiencias terminológicas y conceptuales tanto por parte del accionante como de la Corte, por lo que merece análisis más detenido. Ver también: Expediente 2837-2006, sentencia de 15 de enero de 2008, en que se fundamenta con relación al constitucionalismo social y el Estado Social de Derecho. 
'sintonía' con diversas corrientes filosóficas, incluso teológicas (Tomo I, No. 3, pág. 15, García Bauer), mencionando entre otros a los sistemas personalistas (Tomo I, No. 4, pág. 20, García Bauer), aunque aclarando que no fue propósito de la Comisión definir los diversos tipos de antropocentrismo y humanismo existentes (Tomo I, No. 3, pág. 17, García Bauer).

En las sesiones de la Asamblea Nacional Constituyente se expresó que el artículo $1^{\circ}$ constitucional "determina la orientación personalista y humanista del Estado guatemalteco" partiendo de la naturaleza corporal y espiritual de la persona (Tomo I, No. 21, págs. 15-16, Maldonado Aguirre), y que entre los factores de la personalidad se encuentran: biológico, psíquico, social, físico, intelectual, moral, cuyo desarrollo integral forma parte de la axiología o filosofía de la Constitución (pág. 18, Guzmán Morales; pág. 20, Recinos Figueroa). Sobre el artículo 44 se comentó que, al consagrar los derechos inherentes a la persona humana, no los limita a los contemplados en la Constitución ni a los establecidos por declaraciones o tratados, sino abarca un término 'inherente' de mayor profundidad, referido a los derechos humanos como terminología que reemplazó la de derechos naturales y de derechos del hombre (Tomo II, No. 33, págs. 59 y 78, Larios Ochaita).

El diálogo intercultural adquiere características e importancia singulares en Guatemala, cuya Constitución también reconoce el derecho (personal y comunitario) a la identidad cultural (artículo 58) y la protección de las formas de vida de los diversos grupos étnicos (artículo 66) que nos configuran como país pluricultural. Al respecto, la Corte de Constitucionalidad ha manifestado:

Guatemala se caracteriza sociológicamente como un país multiétnico, pluricultural y multilingüe, en el que se desarrollan simultáneamente diversas culturas, cada una con costumbres y tradiciones propias; de ahí que el gran reto de la Guatemala actual es lograr la existencia de un Estado inclusivo que reconociendo la diversidad y riqueza cultural, construya las bases que permitan su coexistencia y desarrollo armónico, con la finalidad de lograr una sana convivencia social que, basada en el respeto recíproco de la identidad cultural de todas las personas que habitan el 
país, haga viable alcanzar su fin supremo que es la realización del bien común. (Expediente 2906-2017, sentencia de 21 de septiembre de 2017)4.

En un Estado pluriétnico y pluricultural la legitimación democrática es solo una de las formas de legitimación de la autoridad, pues en un mismo territorio pueden (...) confluir autoridades cuya legitimación puede tener (...) origen ancestral. Ambas autoridades están llamadas a buscar maneras de articular y coordinar sus funciones, fomentar una relación basada en el respeto al principio de igualdad de derechos; $y$ (...) favorecer la comprensión, la tolerancia y la amistad entre todas las naciones y entre todos los grupos raciales, étnicos o religiosos, en pro del mantenimiento de la paz (...). (Expediente 4755-2017, sentencia de 1 de marzo de 2018). 


\section{CONCLUSIONES}

La visión de Ratzinger funda los derechos humanos, en última instancia, sobre Dios como creador de la persona y, en este sentido, se inscribe en el iusnaturalismo teológico. Ahora bien, también enfatiza el orden natural como accesible a la razón, pero no como una manera de justificar un derecho nacido de la religión sino, por el contrario, afirmando expresamente que ni a ésta ni a la teología corresponde dictar normas ni soluciones políticas concretas, y rechazando explícitamente la pretensión de un derecho revelado.

Ratzinger ve el fundamento (inmediato) de los derechos humanos en la persona, cuya unidad y carácter universal son la base de la universalidad, indivisibilidad e interdependencia de los derechos. Estos caracteres podrían entenderse simplemente como referidos al concepto jurídico de ámbito de validez', como orientación tendiente a promover interpretaciones armonizantes entre los derechos fundamentales, especialmente en casos de potencial conflicto: es decir, como conceptos instrumentales de técnica o hermenéutica jurídica. Pero para Ratzinger van más allá: no se refieren a los derechos en abstracto como objetos de análisis, sino a cualidades que éstos derivan esencialmente de su mismo carácter de 'humanos' y, por tanto, van inseparablemente unidos a la persona y su dignidad, fungiendo también como límites a la propia noción de derechos humanos, evitando interpretaciones que nieguen lo humano.

Hablar de límites a los derechos humanos no parece intuitivo en una época en que, por el contrario, los discursos tienden a su progresivo ensanchamiento, frecuentemente sin una base o finalidad claras. Sin embargo, vendrían dados por su propio carácter 'humano', en cuanto la persona tiene límites naturales impuestos, no sólo por su evidente limitación física, espacio-temporal, sino más radicalmente por su condición de creatura. Ratzinger invita a "complementar la doctrina de los derechos humanos con una doctrina de los deberes y los límites del hombre" (2008f, pág. 48). En todo esto se hace patente el carácter personalista de su pensamiento.

La Constitución guatemalteca se basa en una concepción de la persona que reconoce la riqueza de sus dimensiones y aspiraciones, buscando 
armonizarlas, tutelarlas y promoverlas. Adopta una apertura iusnaturalista a la inherencia de derechos, más allá de los positivizados tanto en el ámbito nacional como internacional. Con ello se aleja -expresa y decididamente- de los reduccionismos materialistas, individualistas y colectivistas, que han originado los dos extremos ideológicos y políticos que se disputaron la hegemonía global en el siglo XX, y que bajo nuevas formas siguen protagonizando el debate mundial junto a nuevos retos propios de nuestra época.

La primacía de la persona humana así entendida, consagrada como principio fundamental del constitucionalismo guatemalteco, se presta a ser comprendida y desarrollada desde una óptica personalista y, así, fundamentar una visión tanto del ordenamiento jurídico guatemalteco como de los instrumentos internacionales de derechos humanos -que complementan el derecho interno y prevalecen sobre él- que los haga coherentes entre sí, dotándolos de unidad con base en la unidad de la persona.

Un retorno a semejante noción de persona humana -como lo propone Ratzinger- implicaría retomar tanto la capacidad de contemplar el mundo "como naturaleza dotada de un sentido intrínseco" (Massini, 2006, pág. 104) como el carácter relacional constitutivo del ser humano. Ello apunta a su vez hacia los límites de la persona ante la naturaleza -no sólo naturaleza física, sino su propia esencia o 'ecología del hombre', como ha dicho Ratzinger-, su interdependencia respecto de los demás y, por ende, tanto la necesidad como la posibilidad de entrar en diálogo con ellos más allá de barreras culturales, religiosas, socioeconómicas, étnicas, ideológicas, etc. En esto pueden vislumbrarse importantes efectos no sólo jurídicos, sino también económicos, sociales, ambientales, entre otros. Esta es quizá una de las aplicaciones más importantes que las ideas de Ratzinger puedan tener en la actualidad, cuando cada vez se hace más evidente la profunda -y no pocas veces violenta- división e incomprensión que separa a distintos grupos humanos, a nivel global y nacional.

Esto es aplicable no sólo a nivel teórico para comprender la interrelación entre constitucionalismo guatemalteco, ordenamiento jurídico nacional y sistema internacional de derechos humanos, sino también en la práctica 
jurídica en que éstos toman vida. A tal efecto, Ratzinger ha valorado la actividad judicial promoviendo una visión del derecho con una hermenéutica realista, centrada en la prudencia y la justicia, más allá del sistema de leyes que privaría al intérprete del contacto vital con la realidad. A la vez, ha rechazado corrientes hermenéuticas que proponen una labor interpretativa que puede tornarse arbitraria.

Si bien el reconocimiento de los derechos de los pueblos indígenas es un desarrollo positivo del constitucionalismo guatemalteco y latinoamericano, su traducción al lenguaje de los derechos humanos no deja de ser problemática, entre otros motivos, porque pretende aplicar medios jurídicos para resolver problemas que son principalmente de otra naturaleza, invitando a judicializar problemas que más bien requieren soluciones de tipo político y cultural (Gargarella, 2013, pág. 180). La clave personalista del hombre como esencialmente múltiple y diverso puede ser base para una seria reflexión filosófica que, traducida a consecuencias prácticas sobre el quehacer político y jurídico nacional, permita encontrar bases y métodos de armonización entre el ordenamiento jurídico nacional, los sistemas internacionales de derechos humanos, y el pluralismo jurídico que nuestra Constitución también reconoce como elemento constitutivo del Estado ${ }^{5}$. Todo esto es tarea muy necesaria en la actualidad nacional, marcada por profundas crisis de Estado y sociedad.

El pensamiento de Ratzinger nos invita a una apertura espiritual e intelectual, conducente a que tanto los derechos humanos como nuestra realidad pluricultural sean, no eslóganes decorativos ni fuentes de conflicto, sino auténticos caminos de comprensión, de respeto y de paz.

$5 \quad$ La Corte de Constitucionalidad lo ha expresado así: “....para garantizar real y efectivamente los derechos humanos de los pueblos indígenas guatemaltecos debe hacerse acopio del respeto a sus costumbres y formas de organización social, lo que incluye, necesariamente, el reconocimiento de la existencia de un sistema jurídico propio, por medio del que se dirimen los conflictos suscitados en el seno de esas comunidades, permitiendo así la transición de un Estado con visión monista -basado en la existencia de un solo sistema jurídico occidental- a pluralista -en el que coexisten coordinadamente ambos sistemas jurídicos, oficial e indígena-, circunstancia, que esta Corte reconoce y ha sido asentado en distintos fallos" (Expediente 2906-2017, sentencia de 21 de septiembre de 2017). 


\section{BIBLIOGRAFÍA}

Bass, G. (2010). The old new thing. The New Republic. 11 de noviembre. Nueva York, Estados Unidos.

Blanco, P. (2012). Joseph Ratzinger - Benedicto XVI. Un mapa de sus ideas. Biblioteca de Autores Cristianos (BAC). Madrid, España.

Burgos, J.M. (2009). Antropología: una guía para la existencia. 4a edición. Ediciones Palabra. Madrid, España.

(2010). El personalismo: una antropología para el siglo XXI. Philosophia personae. Una antropología para el siglo XXI. II Congreso Internacional. Garnica, F., Ramírez, S. y Puentes, W. (Compiladores). Universidad Católica de Colombia. Bogotá, Colombia.

Buriticá, D. (2014). El concepto de persona humana en la tradición cristiana y su progresión hasta el personalismo. Cuestiones Teológicas. Vol. 41, No. 96, Julio-Diciembre. Medellín, Colombia.

Congreso de la República de Guatemala. (2011). Diario de Sesiones de la Asamblea Nacional Constituyente. Edición digital conmemorativa de los 25 años de vigencia de la Constitución. Ciudad de Guatemala.

(2011). Diario de Sesiones de la Comisión del Proyecto de Constitución (Comisión de los Treinta). Edición digital conmemorativa de los 25 años de vigencia de la Constitución. Ciudad de Guatemala.

Corte de Constitucionalidad. (1986). Expediente 12-86, sentencia de 17 de septiembre de 1986. (2008). Expediente 2837-2006, sentencia de 15 de enero de 2008.

(2011). Expediente 2953-2009, sentencia de 22 de febrero de 2011. (2016a). Expediente 1467-2014, sentencia de 10 de marzo de 2016

(2016b). Expediente 2567-2015, sentencia de 31 de marzo de 2016. (2017a). Expediente 2906-2017, sentencia de 21 de septiembre de 2017.

(2017b). Expediente 943-2017, sentencia de 21 de junio de 2017.

(2017c). Expediente 5956-2016, sentencia de 5 de octubre de 2017.

(2018). Expediente 4755-2017, sentencia de 1 de marzo de 2018.

De León Carpio, R. (S.F.). Catecismo constitucional. Instituto de Investigación y Capacitación Atanasio Tzul. Guatemala, S/A.

Dilthey, W. (1994). Teoría de las concepciones del mundo. Ediciones Altaya. Barcelona, España.

García Laguardia, J.M. (2015). Breve historia constitucional de Guatemala. 2a edición. Editorial Universitaria, Universidad de San Carlos de Guatemala. Guatemala. 
Gargarella, R. (2013). Latin American Constitutionalism, 1810-2010: The Engine Room of the Constitution. Oxford University Press. Nueva York.

Glendon, M.A. (2002). A world made new: Eleanor Roosevelt and the Universal Declaration of Human Rights. Random House. Nueva York, Estados Unidos.

Goodale, M. (2018). Letters to the contrary: A curated history of the UNESCO human rights survey. Stanford University Press. Stanford, Estados Unidos.

Gutiérrez, A. (2017). El neoconstitucionalismo como paradigma epistemológico. Tesis doctoral. Universidad de San Carlos de Guatemala. Guatemala, Guatemala.

Hervada, J. (1996). Historia de la ciencia del Derecho Natural. $3^{\text {a }}$ edición. Ediciones Universidad de Navarra. Pamplona, España.

Jensen, S. (2016). Decolonization -not western liberals- established human rights on the global agenda. Open Global Rights.

(2017). Dejemos descansar en paz a la teoría de las tres generaciones de derechos humanos. Open Global Rights.

Massini, C. (2006). La ley natural y su interpretación contemporánea. Ediciones Universidad de Navarra. Pamplona, España.

Moyn, S. (2010). The last utopia: Human rights in history. Belknap Press, Harvard. Cambridge, Estados Unidos.

Nikken, P. (2010). La protección de los derechos humanos: haciendo efectiva la progresividad de los derechos económicos, sociales y culturales. Revista Instituto Interamericano de Derechos Humanos (IIDH), Vol. 52, julio-diciembre. San José, Costa Rica.

Organización de las Naciones Unidas. (1945). Carta de las Naciones Unidas. San Francisco, Estados Unidos de América.

Ratzinger, J. (1999). La crisis del derecho. Discurso, 10 de noviembre. Universidad LUMSA. Roma, Italia.

(2005a). Fe, verdad y tolerancia. El cristianismo y las religiones del mundo. $4^{\text {a }}$ edición. Ediciones Sígueme. Salamanca, España.

(2005b). Europa en la crisis de las culturas. Conferencia, 1 de abril. Subiaco, Italia.

(2006a). El Dios de la fe y el Dios de los filósofos. Ediciones Encuentro. Madrid, España.

(Benedicto XVI). (2006b). Discurso en la Universidad de Ratisbona. 12 de septiembre. Libreria Editrice Vaticana. Ratisbona, Alemania.

(Benedicto XVI). (2006c). Discurso a los participantes en un Congreso organizado por el Partido Popular Europeo. 30 de marzo. Libreria Editrice Vaticana. Ciudad del Vaticano.

(Benedicto XVI). (2007a). Discurso a los prelados, auditores y oficiales del Tribunal de la Rota Romana con motivo de la Inauguración del Año Judicial. 27 de enero. Libreria Editrice Vaticana. Ciudad del Vaticano. 
(Benedicto XVI). (2007b). Exhortación apostólica postsinodal Sacramentum Caritatis. Libreria Editrice Vaticana. Ciudad del Vaticano.

(Benedicto XVI). (2008a). Discurso ante la Asamblea General de las Naciones Unidas. 18 de abril. Libreria Editrice Vaticana. Nueva York, Estados Unidos.

(Benedicto XVI). (2008b). Discurso preparado para el encuentro con la Universidad de Roma 'La Sapienza'. 17 de enero. Libreria Editrice Vaticana. Roma, Italia.

(Benedicto XVI). (2008c). Discurso a Mary Ann Glendon, embajadora de Estados Unidos ante la Santa Sede. 29 de febrero. Libreria Editrice Vaticana. Ciudad del Vaticano.

(Benedicto XVI). (2008d). Discurso al Tribunal de la Rota romana con ocasión de la inauguración del nuevo año judicial. 26 de enero. Libreria Editrice Vaticana. Ciudad del Vaticano.

(Benedicto XVI). (2008e). Discurso a un Congreso con ocasión del 25 Aniversario de la Promulgación del Código de Derecho Canónico. 25 de enero. Libreria Editrice Vaticana. Ciudad del Vaticano.

(2008f). Lo que cohesiona al mundo. Los fundamentos morales y prepolíticos del estado liberal. Entre razón y religión. Dialéctica de la secularización. Habermas, J. \& Ratzinger, J. Fondo de Cultura Económica. Ciudad de México.

(Benedicto XVI). (2009). Carta encíclica Caritas in veritate. Libreria Editrice Vaticana. Ciudad del Vaticano.

(Benedicto XVI). (2010). Discurso en Westminster Hall. 17 de septiembre. Libreria Editrice Vaticana. Londres, Inglaterra.

(Benedicto XVI). (2011). Discurso en el Parlamento Federal Alemán. 22 de septiembre. Libreria Editrice Vaticana. Berlín, Alemania.

(Benedicto XVI). (2012a). La razonabilidad de la fe en Dios. Audiencia general, 21 de noviembre. Libreria Editrice Vaticana. Ciudad del Vaticano.

(Benedicto XVI). (2012b). Discurso al Tribunal de la Rota Romana por la inauguración del año judicial. 21 de enero. Libreria Editrice Vaticana. Ciudad del Vaticano.

(Benedicto XVI). (2018). La multiplicación de los derechos y la destrucción del concepto de derecho. Liberar la libertad. Fe y política en el tercer milenio. Textos selectos, Vol. 2. Biblioteca de Autores Cristianos (BAC). Madrid, España.

Red de Derechos Humanos y Educación Superior (DHES). (2013). Protección multinivel de derechos humanos. Manual. Bandeira, G., Urueña, R. y Torres, A. (Coordinadores). Barcelona, España.

Romero, J.A. (2018). Teoría hermenéutica contemporánea. Epistemología de las ciencias sociales. Volumen II. 2a edición. Editorial y Librería Kyrios. Guatemala, Guatemala. 